\title{
Hematologic Response
}

National Cancer Institute

\section{Source}

National Cancer Institute. Hematologic Response. NCI Thesaurus. Code C123622.

An evaluation of the hematologic response of the disease to the therapy. 